\title{
Malignant melanoma with osteosarcomatous differentiation in a lymph node metastasis
}

\author{
Jasmine Saleh ${ }^{1}$ (1) | Michael L. Wang ${ }^{2}$ (1) | Paul W. Harms ${ }^{2,3}$ | Rajiv M. Patel ${ }^{2,3}$ (1) | \\ Douglas R. Fullen ${ }^{2,3}$
}

${ }^{1}$ Department of Otolaryngology-Head and Neck Surgery, University of Michigan, Ann Arbor, Michigan

${ }^{2}$ Department of Pathology, University of Michigan, Ann Arbor, Michigan

${ }^{3}$ Department of Dermatology, University of Michigan, Ann Arbor, Michigan

Correspondence

Dr Douglas R. Fullen, Department of

Pathology, University of Michigan, 3261

Medical Sciences I, 1301 Catherine Road, Ann

Arbor, MI 48109-5602.

Email: dfullen@med.umich.edu
Osteocartilaginous differentiation in malignant melanoma is rare and can pose a diagnostic challenge. In previously reported cases, melanomas were predominantly located on acral and mucosal sites, with osteocartilaginous differentiation present in either primary or recurrent lesions. We report a case of a 52-year-old female with malignant melanoma located on the right upper back exhibiting osteosarcomatous differentiation only in the axillary lymph node metastasis. This case serves to highlight that the divergent differentiation can occur in lymph node metastases while being absent in the primary lesion. The patient's medical history, careful histological examination, and immunohistochemistry may be necessary for establishing the correct diagnosis.

\section{KEYWORDS}

differentiation, heterologous elements, malignant melanoma, metastasis, osteosarcomatous

\section{1 | INTRODUCTION}

Malignant melanoma may exhibit divergent differentiation. Reported types of heterologous elements observed in melanoma include fibroblastic/myofibroblastic, Schwannian and perineurial, smooth muscle, rhabdomyosarcomatous, osteocartilaginous, ganglionic and ganglioneuroblastic, neuroendocrine, and epithelial. ${ }^{1}$ Osteocartilaginous differentiation of malignant melanoma is very rare, with only 38 cases being previously reported. ${ }^{2-29}$ The heterologous elements were mostly present in the primary or recurrent lesions, but seen only in the cutaneous metastases in 2 cases and in the lymph node metastases in 2 other cases. ${ }^{6,9,17,25}$ These metastases displayed cartilaginous/ chondrosarcomatous differentiation. Rhabdomyosarcomatous differentiation has also been reported in metastases, while not being observed in the primary melanoma. ${ }^{30}$ We present an extraordinary case of malignant melanoma of the right upper back with osteosarcomatous differentiation restricted to the lymph node metastasis.

\section{2 | CASE PRESENTATION}

A 52-year-old female with no known history of malignancy presented with a skin lesion on her right upper back. On physical examination, a
$2.5 \mathrm{~cm}$ raised, variegated, hyperpigmented skin lesion with irregular borders was identified (Figure 1). The lesion had been present for many years and remained asymptomatic until 1 year prior to the initial biopsy, when it started to itch. The patient reported that it became tender and blistered 7 months later.

An initial biopsy of the primary skin lesion was performed at an outside facility and reviewed for patient management in our Multidisciplinary Melanoma Clinic. A subsequent excisional biopsy for microstaging was performed at our institution for final melanoma prognostic parameters. Histological examination of the microstaging specimen revealed cytologically atypical epithelioid and spindled cells with finely vesicular chromatin and conspicuous nucleoli within the epidermis and dermis, consistent with superficial spreading melanoma invasive to Clark level IV and $1.65 \mathrm{~mm}$ Breslow thickness (Figure 2). The mitotic rate was $5 / \mathrm{mm}^{2}$. There was no lymphovascular invasion, ulceration, or osteosarcomatous differentiation present within either specimen. Immunohistochemical staining of the primary tumor demonstrated that constitutive cells were positive for S-100, HMB-45, MiTF, SOX-10, and p16. Melan-A, BRAF V600E, and p63 were negative.

A wide local excision and sentinel lymph node biopsy were performed. The sentinel lymph node biopsy revealed a metastatic neoplasm with cytomorphology identical to the patient's primary 


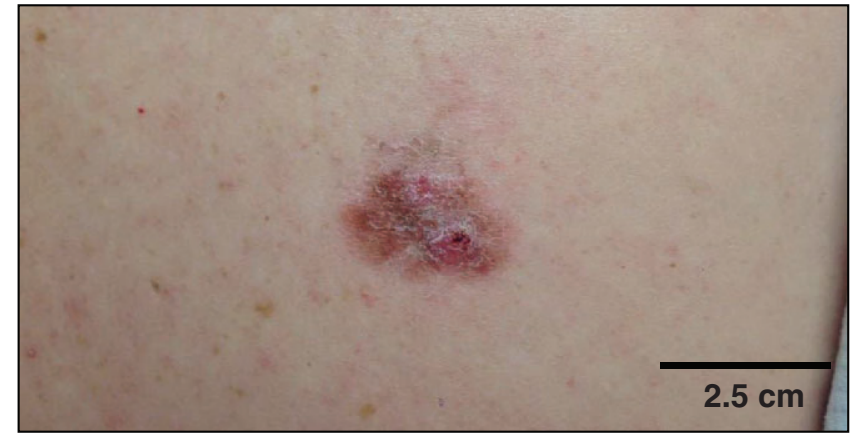

FIGURE 1 Clinical appearance of residual primary melanoma on the right upper back following initial biopsy

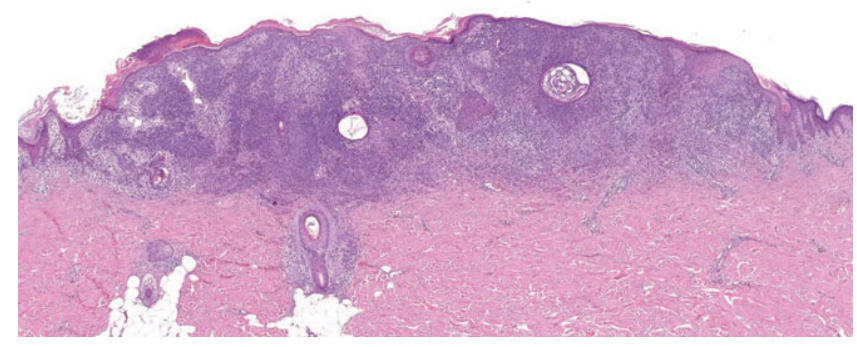

FIGURE 2 Microstaging excision of melanoma reveals a superficial spreading melanoma invasive to Clark's level IV and $1.65 \mathrm{~mm}$ Breslow thickness $(H \& E$, original magnification $\times 23$ )

melanoma (Figure 3). The tumor was intimately associated with malignant osteoid in keeping with focal osteosarcomatous differentiation. No cartilaginous differentiation was identified. Malignant cells in the metastatic lymph node deposit were immunohistochemically positive for S-100, MiTF, and SOX-10, but failed to express HMB-45, and Melan-A (Figure 4).

The patient had a completion lymph node dissection of the right axilla. The patient's American Joint Committee on Cancer stage was IIIA (T2a, N1, MO). She was subsequently lost to follow-up 1 month after the lymph node dissection.

\section{3 | DISCUSSION}

Metastatic malignant melanoma with osteocartilaginous differentiation has been reported in a very small number of case reports. Divergent heterologous elements have been observed in various primary locations, including subungual sites of the fingers and toes, mucosal areas in the nose, mouth, and vagina, and other sites of the body including, the face, back, and shoulder. ${ }^{1}$ However, previously reported cases were predominantly of melanomas from subungual, acral, and mucosal sites, with osteocartilaginous differentiation present in the primary or recurrent lesion. ${ }^{1}$ Our case is extraordinary in that only the lymph node metastasis revealed osteosarcomatous heterologous elements, with no evidence of divergent differentiation observed in the primary lesion in the routine sections examined.

The mechanism of osteosarcomatous differentiation in metastatic melanoma has not been well characterized. Some cases reported ossification in melanomas that developed at sites of previous surgical trauma, suggesting that the divergent differentiation may represent a
(A)

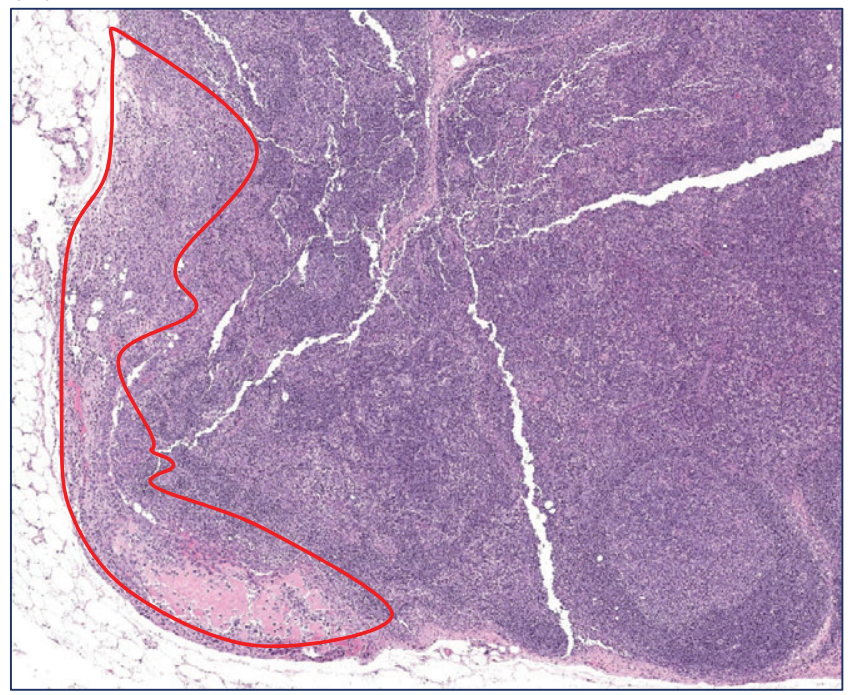

(B)

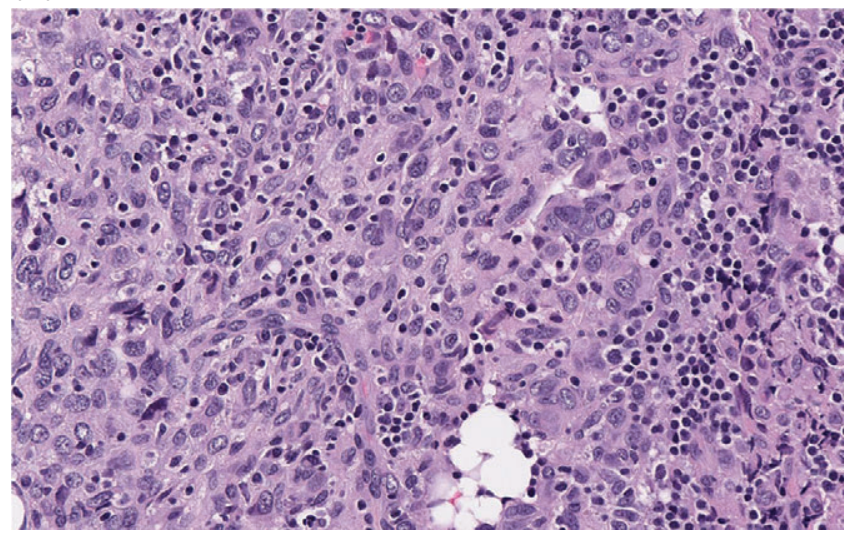

(C)

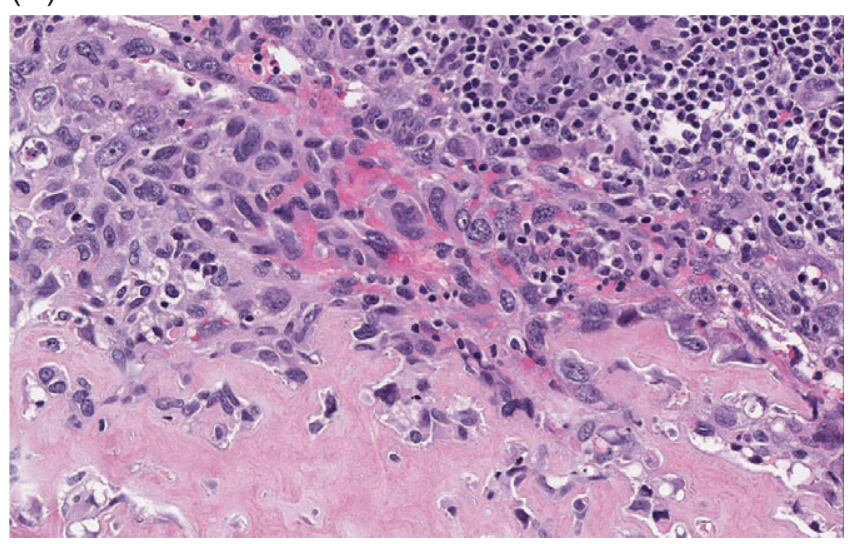

FIGURE 3 Metastatic melanoma (outlined in red) is identified in the right axillary sentinel lymph node with focal osteosarcomatous differentiation $(A)(H \& E$, original magnification $\times 28)$. High-power magnifications of melanoma at a distance from the osteoid (B) and adjacent to the osteoid $(\mathrm{C})$ are shown (H\&E, original magnification $\times 400$ )

reparative response to injury. ${ }^{25}$ It has also been hypothesized that melanoma cells undergo mesenchymal metaplasia to form osteosarcomatous elements. ${ }^{25}$ In addition, invading melanoma cells in a lymph node may induce molecular cascades that promote further proliferation of tumor cells and activate subsequent divergent differentiation. ${ }^{25}$ 
Primary Melanoma
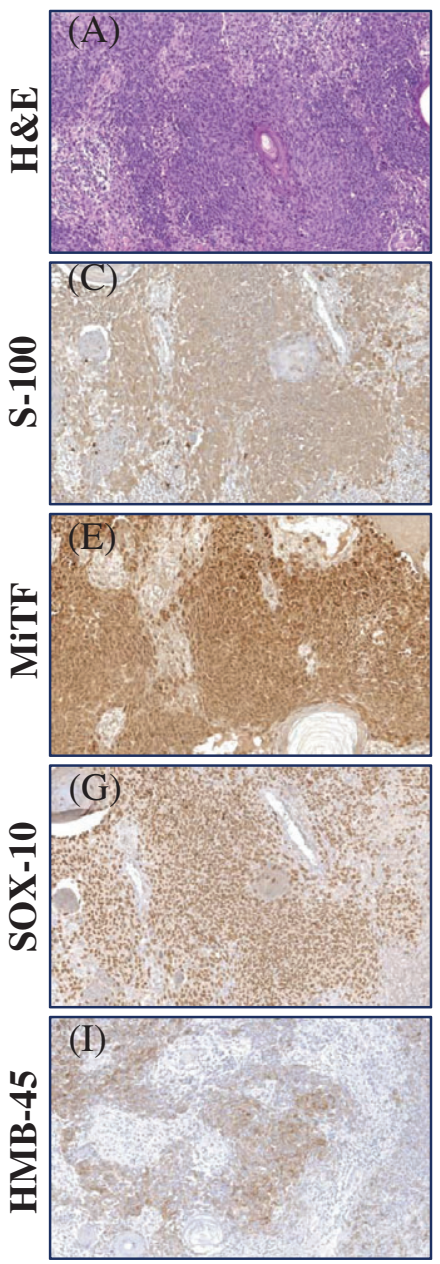

Metastasis
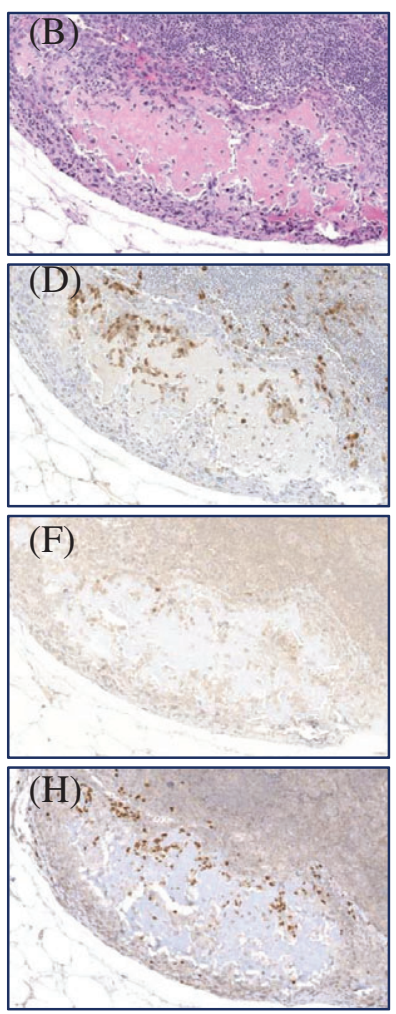

(J)

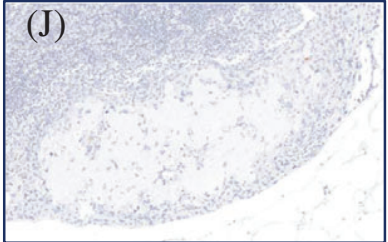

FIGURE 4 Osteosarcomatous differentiation is not observed in the primary lesion ( $A, H \& E)$ but rather in lymph node metastasis $(B, H \& E)$. There is expression of S-100 (C, D), MiTF (E, F), and SOX-10 (G, H) in both the primary melanoma and metastasis. Loss of HMB-45 (I, J) is noted in the metastasis compared to the primary (original magnification $\times 152$ )

Melanomas with osteogenic and/or cartilaginous differentiation can pose a diagnostic challenge. They can mimic various other tumors, including metaplastic carcinomas, sarcomas, neuroendocrine tumors, lymphomas, or germ cell tumors. ${ }^{25}$ Of the previously reported 38 cases with osteocartilaginous differentiation, 9 were initially misdiagnosed as either osteosarcoma, ${ }^{10-12,17,27}$ chondrosarcoma, ${ }^{19,21,25}$ or an extraosseous osteogenic sarcoma. ${ }^{3}$ In our case, the absence of primary bony involvement, adjacent non-osteosarcomatous melanoma in the metastasis, expression of melanocytic markers by immunohistochemistry (eg, S-100, MiTF, and SOX-10), histological examination revealing identical morphology in a subset of metastatic malignant to those seen in the primary lesion and foci of osteosarcomatous differentiation supported our final diagnosis.

Distinguishing melanoma with osteosarcomatous differentiation from osteosarcoma is clinically very significant, as these diseases require different treatments. ${ }^{19}$ Furthermore, osteosarcoma rarely metastasizes to regional lymph nodes and often responds to chemotherapy, whereas metastatic melanoma is not typically responsive to conventional chemotherapy. ${ }^{19}$ Our findings suggest that melanoma should be considered in the differential diagnosis for a metastatic bone-forming malignancy of unknown primary in a patient with a history of melanoma, regardless of whether osteosarcomatous differentiation was present in the primary tumor. As in our case, demonstration of melanocytic marker expression may be useful for supporting the diagnosis of melanoma in such cases. The prognosis of malignant melanoma with osteosarcomatous differentiation remains unknown due to the small number of reported cases with significant follow-up. ${ }^{25}$

\section{CONCLUSION}

Melanoma with osteosarcomatous differentiation has been documented in a very small number of cases and may pose a diagnostic challenge. Melanomas with divergent heterologous elements can mimic various other tumors that may require different treatments regiments. Attention to the patient's past medical history and careful histopathologic and immunohistochemical examination of representative patient specimens will assist in making the correct diagnosis and ensure appropriate subsequent clinical management.

\section{ORCID}

Jasmine Saleh (D) http://orcid.org/0000-0003-2896-6299

Michael L. Wang (D) http://orcid.org/0000-0003-2777-1676

Rajiv M. Patel (D) http://orcid.org/0000-0002-1521-4947

\section{REFERENCES}

1. Banerjee SS, Eyden B. Divergent differentiation in malignant melanomas: a review. Histopathology. 2008;52:119-129.

2. Urmacher C. Unusual stromal patterns in truly recurrent and satellite metastatic lesions of malignant melanoma. Am J Dermatopathol 1984; 6 Suppl:331-335.

3. Grunwald $\mathrm{MH}$, Rothem A, Feuerman EJ. Metastatic malignant melanoma with cartilaginous metaplasia. Dermatologica. 1985;170: 249-252.

4. Weidner N, Flanders DJ, Jochimsen PR, Stamler FW. Neurosarcomatous malignant melanoma arising in a neuroid giant congenital melanocytic nevus. Arch Dermatol. 1985;121:1302-1306.

5. Moreno A, Lamarca J, Martinez R, Guix M. Osteoid and bone formation in desmoplastic malignant melanoma. J Cutan Pathol. 1986;13: 128-134.

6. Brisigotti M, Moreno A, Llistosella E, Prat J. Malignant melanoma with osteocartilaginous differentiation. Surg Pathol. 1989;2:73.

7. Pellegrini AE, Scalamogna PA. Malignant melanoma with osteoid formation. Am J Dermatopathol. 1990;12:607-611.

8. Nakagawa H, Imakado S, Nogita T, Ishibashi Y. Osteosarcomatous changes in malignant melanoma. Immunohistochemical and ultrastructural studies of a case. Am J Dermatopathol. 1990;12:162-168.

9. Lucas DR, Tazelaar HD, Unni KK, et al. Osteogenic melanoma. A rare variant of malignant melanoma. Am J Surg Pathol. 1993;17:400-409.

10. Golouh R, Zidar A. Subungual osteogenic malignant melanoma: a case report. Int J Surg Pathol. 1997;4:249-253.

11. Hoorweg JJ, Loftus BM, Hilgers FJ. Osteoid and bone formation in a nasal mucosal melanoma and its metastasis. Histopathology. 1997;31: 465-468.

12. Banerjee SS, Coyne JD, Menasce LP, Lobo CJ, Hirsch PJ. Diagnostic lessons of mucosal melanoma with osteocartilaginous differentiation. Histopathology. 1998;33:255-260.

13. Cachia AR, Kedziora AM. Subungual malignant melanoma with cartilaginous differentiation. Am J Dermatopathol. 1999;21:165-169. 
14. Ackley CD, Prieto VG, Bentley RC, Horenstein MG, Seigler HF, Shea CR. Primary chondroid melanoma. J Cutan Pathol. 2001;28:482-485.

15. Takeshita H, Miwa T, Furukawa M. Osteocartilaginous differentiation of mucosal melanoma in the sinonasal cavity. Ann Otol Rhinol Laryngol. 2002;111:1112-1115.

16. Giele H, Hollowood K, Gibbons CL, Wilson DJ, Athanasou NA. Subungual melanoma with osteocartilaginous differentiation. Skeletal Radiol. 2003;32:724-727.

17. Iwata $\mathrm{Y}$, Usuda T, Toya K, et al. Malignant melanoma with osteocartilaginous differentiation. Skin Cancer. 2005;20:33-38.

18. Fukunaga M. Osteogenic melanoma. APMIS. 2005;113:296-300.

19. Emanuel PO, Idrees MT, Leytin A, Kwon EJ, Phelps RG. Aggressive osteogenic desmoplastic melanoma: a case report. J Cutan Pathol. 2007;34:423-426.

20. Slavik T, Hannah M, Schroder RA. Primary chondroid melanoma of the nasal skin: a rare melanoma variant at a previously undocumented site. J Cutan Pathol. 2007;34:427-430.

21. Rinaggio J, Hameed M, Baredes S. Melanoma with cartilaginous differentiation originating within the mucosa of the nasal cavity. Oral Surg Oral Med Oral Pathol Oral Radiol Endod. 2008;106:861-865.

22. Hanley KZ, Weiss SW, Logani S. Melanoma with cartilaginous differentiation: diagnostic challenge on fine-needle aspiration with emphasis on differential diagnosis. Diagn Cytopathol. 2009;37:51-55.

23. Piana S, Valli R, Ricci C. Epidermotropic chondroid metastasis of melanoma: report of a case of metastatic melanoma with previously unreported morphological features. Am J Dermatopathol. 2009;31:301-304.

24. Murali R, McCarthy SW, Bothman J, et al. Melanoma exhibiting cartilaginous differentiation. Histopathology. 2010;56:815-821.
25. Sundersingh S, Majhi U, Murhekar K, Krishnamurthy R. Malignant melanoma with osteocartilaginous differentiation. Indian J Pathol Microbiol. 2010;53:130-132.

26. Mete O, Bilgic B, Buyukbabani N. A tumor with many faces: metastatic malignant melanoma with extensive cartilaginous differentiation. Int J Surg Pathol. 2010;18:217-218.

27. McKay KM, Deavers MT, Prieto VG. Chondroid melanoma metastatic to lung and skin showing SOX-9 expression: a potential diagnostic pitfall. Int J Surg Pathol. 2012;20:169-172.

28. Joana Devesa P, Labareda JM, Bártolo EA, Santos MF, Vale EM. Cartilaginous melanoma: case report and review of the literature. An Bras Dermatol. 2013;88:403-407.

29. Am A, Wang W-L, Lazar AJ. Primary chondro-osseous melanoma (chondrosarcomatous and osteosarcomatous melanoma). J Cutan Pathol. 2018;4:146-150.

30. Campbell K, Kumarapeli AR, Gokden N, Cox RM, Hutchins L, Gardner JM. Metastatic melanoma with dedifferentiation and extensive rhabdomyosarcomatous heterologous component. J Cutan Pathol. 2018;45:360-364.

How to cite this article: Saleh J, Wang ML, Harms PW, Patel RM, Fullen DR. Malignant melanoma with osteosarcomatous differentiation in a lymph node metastasis. J Cutan Pathol. 2018;45:701-704. https://doi.org/10.1111/cup.13283 